\title{
Deficiencies of existing public transport system and a proposal for integrated hierarchical transport network as an improvement options: a case of Dhaka city.
}

\author{
Maher Niger \\ (Lecturer, Department of Architecture, Ahsanullah University of Science and Technology, Bangladesh)
}

\begin{abstract}
Public transport plays an important role in providing easy and affordable accessibility and mobility for dwellers in a city. This demand for transportation is brought about by the increased population of connecting nodes, cities, the rural-urban migration, and the scope for socio-economical facilities i.e. better opportunities for jobs, health facilities and educational scope etc. thus the economic viability of the people which leads to an increase in the usage of private vehicles. Dhaka is an over densely populated city and its transport system comprised of many different modes of travel - both motorized and non-motorized - using the same road space - resulting in a high level of operational disorder, that significantly diminishes the efficiency and effectiveness of the existing transport uses. Dhaka is experiencing lots of traffic congestion and a great lack of traffic management. There has been no study dedicated to overcome the situation. Therefore, there is an urgent need to introduce a well-organized, properly scheduled rapid mass transit system minimizing the existing deficiencies. In this paper, an attempt has been made to identify the deficiencies of existing public transport system to put forward for an appropriate rapid mass transit system to recover the huge demand. An overview of the existing modes of travel and operation characteristics has been described. Finally, some proposals for integrated hierarchical transport network options are highlighted with the context of prevailing land use and transport characteristics, socio-economic context of Dhaka Metropolitan city. The findings of this research help planners and decision makers to optimize the investment in transport infrastructure.
\end{abstract}

Keywords - Dhaka city, Hierarchy, Mass transit, Network, Public transport deficiencies.

\section{INTRODUCTION}

Public transport is a collection of modes of transport which are available to the public irrespective of ownership [1], also called mass-transit in a city context. It can be provided by various types of modes; however, in most urban centers in developing cities, it is provided by a wide range of buses and minibuses. Public transport plays a crucial role in the overall success of a city's transportation system. It sustains mobility of the working class unable to afford private vehicle, to those who can't have their own car, helps in creating and maintaining livable communities with high density land use, relieves congestion, assures long term sustainability in terms of shared resource consumption and being responsive to the environment. It also provides large number of transport opportunities at once in order to meet the maximum demand during the peak hours. Studies have shown, in trying to control congestion on the roads, options like the integration of land use and transport, widening or construction of new roads have been effective. However, the provision of public transport has proven to be much efficient in controlling congestions and to have efficient public dispersion.

Public transport system is a process evolving over time and is not always directly responsive to the changing demand vs. supply to achieve equilibrium overnight, like a private vehicle solution. Capital investment is simply too high for a mass transit network. Then the question arises as to how best to cope with increasing change in demand with the existing infrastructure public transport infrastructure. The public transport infrastructure investment is directly proportional to the possible economical turnover and the population serviced. Experiences in most countries show that construction $\mathrm{f}$ new roads or widening of roads only solves the problem of congestion for a while [2]. It encourages the use of private vehicles which lead again to congestion and its associated side effects like air and noise pollution [3]. As a result of the financial constraints faced by many countries, especially the developing countries, an improved public transport system seems the most likely solution to controlling congestion on the roads as compared to investing in the construction of road infrastructures [4]. This move to tell us that the provision of an efficient public transport is a more likely answer to curbing congestion in future plans of a city [5].

Dhaka, the capital city of Bangladesh is one of the most over-populated cities in the world. It houses about 14 million populations within 2,000 sq. km. land area (which means 7000 persons $/ \mathrm{sq} . \mathrm{km}$ ). With a growth rate of about 8 percent per year, it is expected to be the seventh position in terms of population by 2015 [6]. Rapid population increase over the past decade has resulted in its transport services not being able to respond to the travel needs of its residents. Demand has not been matched by sufficient investment in transport 
infrastructure, services and management. Traffic and public transport conditions in Dhaka have seriously deteriorated, characterized by traffic congestion and delays, inadequate traffic management, public transport crisis, unaffordable and inaccessible public transport for many people, high accident rates, and increasing air pollution problems [7]. The crisis in public transport is largely the result of growing concentration of population and economic activities, and inadequate public transport systems. However, the projected population of the city is expected to be around 16 million by the year 2015 and around 24 million by 2021 [8]; already alarming and will make the situation more critical if appropriate measures are not taken to tackle the increasing travel demand. Further, the road hierarchy is poorly established and most new development is taking place without any coherent road system [9]. This rapid population growth together with the limited space available for new transport infrastructure will further aggravate the heavy congestion in Dhaka. The existing road network in metropolitan Dhaka needs a planned restructuring to support an efficient public transport system. This restructuring should be based on standard and functional road classification system, which provides a hierarchy of roads, viz: Local streets, Collectors, Arterials, Access Controlled Freeways etc.

\section{Transport In DhaKa City}

Being the administrative, commercial \& cultural capital of Bangladesh, the Mega City Dhaka has a major role to play in the socioeconomic development of the country and in the era of regional and sub-regional cooperation. But the existing transportation system is a major bottleneck for the development of the city. Unplanned urbanization, especially poor transportation planning and lower land utilization efficiency, has turned the city into a dangerous urban jungle [10] The rapid rise in population along with increased and versatile urban land use patterns has generated considerable travel demand as well as numerous transport problems in Dhaka City. It has resulted in a deterioration of accessibility, level of service, safety, comfort, operational efficiency and urban environment. The transportation system of Dhaka is predominantly road based and nonmotorized transportation (mainly rickshaws) has a substantial share. Although a 37-km long rail-road passes through the heart of the city but it has no contribution to city's transport system. There is a limited use of waterways, especially for freight movements. The existing transportation infrastructure in Dhaka could not bear the current traffic loads. The level of service and options of transport modes are not at all convenient for the passengers and either for the environment [11]. Dhaka's transport environment is characterized by mixed-modes transports using the same road space, traffic congestion, delays, mismanagement, conflict of jurisdictions, poor coordination among organizations and increasing environmental problems.

\subsection{Road network:}

Established on the banks of the river Buriganga, Dhaka has been increasing in north-south direction. With the expansion of the city, the road network of the city has also been growing time to time. The major roads in the old part of Dhaka have been developed in the east-west direction and major roads in the new part have been developed in the north south direction. The road network of the city had never been planned specifically in cognizance with the well-developed process of trip generation, trip distribution, modal split and route assignment. As a result, an irregular pattern of network, rather than a more efficient pattern such as gridiron or redial-circumferential pattern, has been developed [12]. Dhaka's road network is nearly $3000 \mathrm{~km}$ [13], of which $200 \mathrm{~km}$ primary roads, $110 \mathrm{~km}$ secondary roads, $50 \mathrm{~km}$ feeder roads and rest $2640 \mathrm{~km}$ narrow roads, with few alternatives and connector roads and it represents the proportion of road surface to built-up area hardly $7 \%$ as against $25 \%$ recommended for a good city planning [14]. With the exception of some well-planned residential areas, in most of the areas the road network is quite narrow and alignment is poor. Widths of streets, within the old part of Dhaka are narrower than other newly developed parts. There are only a few pedestrian overpass and underpass. At present two flyovers are finished and some others are proposed for construction. The existing road network in metropolitan Dhaka needs a planned restructuring to support an efficient transport system. This restructuring should be based on standard and functional road classification system, which provides a hierarchy of roads.

\subsection{Road transport modes:}

Metropolitan Dhaka has traditionally been served by a wide variety of transport modes. These modes can be broadly classified into two groups, motorized transport (viz. bus, mini-bus, truck, car, auto-rickshaw, auto-tempo, motorcycle etc.) and non-motorized transports (viz. rickshaw, rickshaw van, bicycle, push cart etc.). Motorized Transport: Estimation from the data provided by 'Statistical Year Book of Bangladesh' reveals that the motor vehicle fleet in Bangladesh is growing as an average rate of 7\% per year. But DUTP-II (1998) claims that the vehicle population on road is growing as an average rate of $10 \%$ annually. Non-Motorized Transport: Reliable estimate of non-motorized vehicle fleet is more difficult to obtain. DCC limits the number of license issued to rickshaw owners to some 70,000. However, unofficial estimates claim that the number of rickshaws plying in Dhaka city is three times the DCC figure [15]. 


\subsection{Terminals:}

A terminal station is a central location and important traffic generating mode from where buses may originate, terminate or stop over en route to sub serve the overall route network in a given catchments area. It provides passenger amenities and also provides passenger information regarding services. It is an important traffic junction which is a focal point for smooth running of services. Dhaka is served by three inter-city bus terminals and four BRTC bus depots exist where the terminals are conveniently located with respect to the corridors they serve: Saidabad- Southern Corridor, Mohakhali- Northern Corridor, Gabtoli North-Western Corridor. City Corporation owns the terminals of Dhaka city. While terminals should be the place for passenger boarding and alighting, driver's refreshment and passenger waiting facilities, in Dhaka the main function of the terminal can be described as rather bus depot. Most of the privately owned buses take shelter in the terminals during idle time and as such it remains overcrowded by the idle bus drivers, helpers and union members. All these along with the poor supervision and maintenance practice have made the terminal area as most unwelcome place for the passengers and on duty drivers.

\subsection{Overview}

\section{Existing Public Transport System Of Dhaka City}

Existing mass transit system in metropolitan Dhaka is mainly characterized by large bus, mini bus and human hauler/auto-tempo. Bus and minibus routes tend to be concentrated along the limited number of arterial roads, in a generally north-south orientation. Human hauler routes are more dispersed, penetrating narrower roads, and include more east-west linkage. The 2004 Dhaka STP divides buses into several categories: minibuses (41\%), microbuses (30\%), large buses (13\%), auto tempo/laguna maxi (12\%), and staff and school buses (4\%). Residents of Dhaka understand the bus system as divided mainly into ticket buses and local buses. Ticket buses have set stoppages on their routes, which can be located by the companies' respective ticket counters. Their fares are collected on the curb side from ticket sellers associated with each private company, and have a single conductor on board who checks tickets at the doorway. Almost all of the large buses are ticket buses. Local buses have stoppages that are unmarked and have on-board fare collection. Local buses can also be boarded and alighted from at any point on the route, at the conductor's discretion. There are a handful of large buses that operate as local buses, but the vast majority of local buses are minibuses.

Buses in Dhaka city are operated both in private and public ways. The private sector is dominating and provides a monopoly service (95\% of total bus services) compared to public sector operation. The present bus services provide inefficient, unproductive, and unsafe level of services. Long waiting, delay on plying, overloading, discomfort, and long walking distance from the residence/work place to bus stoppages are some of the obvious problems that confront the users in their daily life.

Today's bus operation in Dhaka is characterized with the existence of 750 individual bus owners. Dhaka city has only around 2500 buses as public transport whilst the current demand is more than 5,000. However, only 1,300 of the existing buses are playing of which less than 200 are of improved quality [16]. Public transport of the city is poor and disorganized with limited coverage [17]. The present mass transit mode in the form of bus transport has not been able to be popular and grow its share of catering demand. The poor institutional and regulatory framework, reluctance to enforce existing legislation, and lack of enforcement reduce the capacity of existing roads [18].

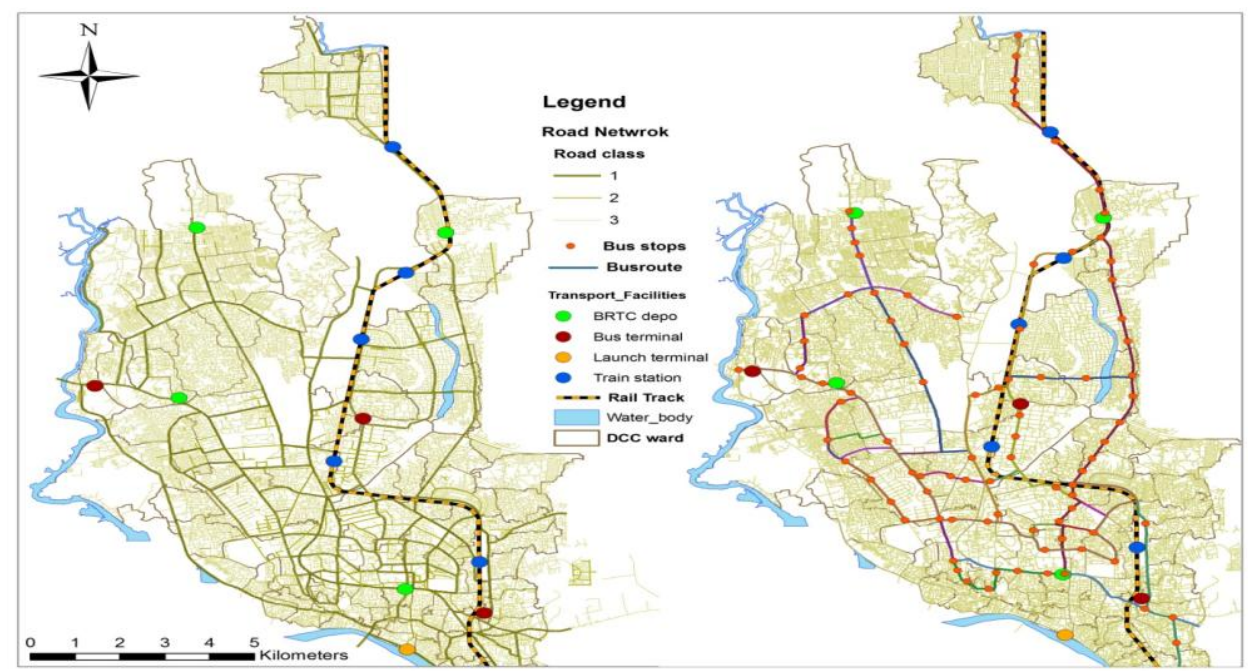

Figure 1: Road network and existing bus route and bus stops of Dhaka city (Source: Author) 


\subsection{Bus stop and route location}

Though the bus route lists of Bangladesh Road Transport Authority (BRTA) shows a total of 34 routes in Dhaka City, including the sub-routes of different main routes it becomes 46 in total of which 13 routes are not presently in operation [19] [20]. Majority of the routes are in north-south direction.

Normally bus stops are attributes of transport services which are designated place where a public transport bus stops for the purpose of allowing passengers to board or leave a bus. Most passengers walk to reach bus stops, and 500 meter is considered a convenient walking distance for human beings [21]. A study on bus routes and stoppages [22] found majority of the bus riders in Dhaka city use a particular bus services for the cheaper fare and walk to or from the bus stop. The study also found that the majority of the stops are not located within a comfortable walking distance. Most of the users have to walk for 15-20 minutes or 1-1.5 km and wait for a period of 20-30 minutes for a bus. Bus/other transit stoppages and the city bus terminals suffer from poor operation and management. Most of the stoppages are in bad condition, e.g., unauthorized use, blocked by parked vehicle and roadside activities and water logging in rainy season. The basic elements of a stoppage such as proper shelter, route information, schedule information and passenger waiting facilities are missing in most of the stoppages. Buses and other Para-transit vehicles most often stand at a place away from the designated bus stoppage. This creates problem of reduction in effective road width and lack of safety and comfort for transit users.

\section{INSTITUTIONAL SETUP}

In Dhaka, three separate bodies such as Rajdhani Unnayan Katripakkha (RAJUK), Dhaka City Corporation (DCC) and Dhaka Metropolitan Traffic Police (DMTP) are thought to be responsible for construction of new transport infrastructures, physical maintenance of road elements and management of traffic operations respectively. But there is no formal accountable interrelationship among these three agencies. The public sector entity, Bangladesh Road Transport Corporation (BRTC), operates less than $2 \%$ of the buses. The overall bus operations are regulated by a number of bodies with overlapping mandates. The Bangladesh Road Transport Authority (BRTA) is empowered to regulate public transport vehicles. The Road Transport Committee (RTC) is appointed by the BRTA to award route permits. The Dhaka Transport Coordination Board (DTCB) plans and coordinates public transport services. The Dhaka Metropolitan Police (DMP) is responsible for enforcing regulations. The Dhaka City Corporation (DCC) is responsible for overall municipal governance and administration. Development partners such as the World Bank have provided support to these authorities in infrastructure development, institutional strengthening and policy support. Other key stakeholders include bus owners (individuals or companies), bus workers, and commuters, owners of other modes of transport, civil society, the media, and politicians.

\section{Deficiencies In Existing Public Transport System}

Current supply of mass transit is much lower than the actual demand. Not only the lack of this supply, there are also many other deficiencies in the existing system of mass transit. Japan Bank for International Cooperation (JBIC) data sources reveal that service deficiencies indicated by users of rickshaw are crowded condition of bus, long waiting time, lack of easy transfer, bus stops are not near from origin, long boarding time. Service deficiencies indicated by bus users are discomfort and congestion. A survey on pedestrians detected service deficiencies in the form of long waiting time, long travel time, lack of comfort, lack of stoppages etc. These deficiencies can be categorized as land use and road limitations, operational weaknesses, and user's points of view.

\subsection{Land use and roadway deficiencies \\ a) Limited road space}

As in many other cities in the region, systematic bus route planning based on a cycle of monitoring, planning, and implementing adjustments to the network is not in place in Dhaka. Total space occupied by roads and streets of Dhaka Metropolitan City is only 9\% of its total space while that of other mega cities cover approximately $25 \%$. Though $9 \%$ of road area of the city is available, pavement area is only $6 \%$ of total area [23].

\section{b) Lack of accessible road}

In Dhaka city, there is a lack of sufficient accessible road. It is estimated that among the existing road network about half of the road lacks sufficient width to accommodate motorized emergency vehicles. In Dhaka city out of $1286 \mathrm{~km}$ road about $821 \mathrm{~km}$ of road is found to be accessible (if road width is equal and more than $4.5 \mathrm{~m})$ to motorized vehicles [24]. 


\section{c) No road network pattern}

As road network of Dhaka City evolved haphazardly without any plan and always to meet short term travel need, the total road network does not show any well defined configuration. Instead, it is expanded eccentrically in the north-south direction and allowing uncontrolled ribbon development.

\section{d) Un-organized and non integrated road network}

During last twenty to thirty years, significant road development has been taken place to cope with sudden transformation of the city from provincial town to the capital of the country. But most of the transport developments have been driven by ad hoc considerations having no explicit focus on analysis of existing demand or future requirements. As a result, the road network of the city is not organized and integrated in terms of connectivity.

\section{e) Absence of east west continuous road}

Present public transport problems are the lack of integration between land use and transport system. In the city, there is not a single continuous main road in east-west direction. The road, which are existing in this direction all are formed as a connecting road or link road. Therefore, vehicle cannot move thoroughly in that direction. Absence of east-west connection has become the major problem for the entire road network of Dhaka. Presently, such requirements are meeting by relatively narrow and poorly aligned roads, which are far beyond to meet the existing demand in terms of capacity, speed and level of service.

\section{f) Lack of bus lay on roads}

There is very few designated place for bus stoppage in road side of Dhaka city. Most of the bus stop in road side haphazardly with competition attitude and alighting and boarding passenger dangerously. This makes always crowed on road side and influence pedestrian to move on road as well as decreases the effective width of the carriage way.

\subsection{Operational deficiencies}

\section{a) Mixed operation in major roads}

Road network of Dhaka city is characterized by mix traffic system. All types of vehicles, both motorized and non-motorized vehicles are in operation on each and every road, except some NMT restricted routes. Where, all types of vehicles are played on the road, majority of road spaces occupied by rickshaw. Because of the presence of non motorized vehicles, travel speed is significantly reduced for motorized vehicles and a huge congestion occurred. Even where non-motorized vehicles are restricted, the majority of road space is occupied by three wheeler vehicles.

\section{b) Low roadway capacity and speed}

Due to the complex mixture of motorized and non-motorized traffic and non-lane based movement over the Dhaka city road network, the capacity \& speed of vehicles has abruptly decreased. The capacity of road lane and speed of the transport mode are very low compared to other capital cities in the world. That is how the city is facing huge traffic congestion at everywhere of the Dhaka city.

\section{c) Absence of bus priority measure}

Public transport is currently not given any priority over other vehicle types and road users. Various forms of bus priority ranging from traffic signal priority measures and bus lanes to possibly dedicated bus-ways should be considered for application in Dhaka. There is no bus only routes or segregated bus lane on roads.

\section{d) Poor maintenance and surface condition of roads}

The surface conditions of most of the roads are very poor. The surface of the roads are not smooth, as a result, journey through vehicles on such roads is not comfortable. Because of the absence of periodic maintenance of the roads, a lot of potholes exist on the surface of the roads. Rain water is stored in these potholes and surface becomes worst. Travel on such roads is very much risky and accidents may occur on such roads. If vehicles are operated continuously on such roads, vehicle's parts may damage.

\section{e) Road space occupied other than traffic}

Most of the roads are not fully used by traffic. Presence of dustbin on roads is very common in Dhaka city. This significantly reduces the effective road width for traffic use. Road spaces are also occupied by hawkers and retailer traders. In many places, construction materials for building are placed on the road. These cause reduction in effective road width and make the road unsafe for vehicles. Again, on-street parking also reduces road spaces and hinders smooth flow of traffic. 


\section{f) Fragmented ownership}

Buses, which are main mass transit system in Dhaka, are operated by government authority and by privately. The BRTC, which operates under immunity from regulation by licensing authorities, owns a total of 306 buses operating on 15 routes in Dhaka. BRTC does not actually operate the buses, but sub-contracts out the operations to private operators. The main problem of privately operated bus services is that buses are owned by a large number of operators and also numerous small operators. There are many operators who have only 2 to 3 buses and some private bus operators have 30 or more buses. Multiple operators competing in same route, often leads to competition which results in results in inefficient road use.

\section{g) Deficient and improper place of bus terminal}

All terminals are poorly designed with respect to terminal system requirements. Many components of the system are totally absent along with some basic amenities. Utter disorder in using the terminal space, lack of management and indiscipline of drivers and passengers are other reasons for congestion all those inter-city bus terminals. Fulbaria Road is the main terminus for intra-urban buses, which also experiences extreme congestion, mainly induced by buses lying over the whole road haphazardly and absence of terminal facilities. Moreover, there is an acute shortage of bus stands with adequate facilities throughout the city (except recently introduced Premium/BRTC services). Hence buses frequently stop here and there affecting smooth flow of traffic. Besides this there are so many deficiencies in regulatory measure like poor loading and unloading, on street ticket counter etc.

\section{h) Non coordinated transport system}

The existing modes and sub-modes (bus-water-rail-NMT) are acting independently of each other. STP survey data shows that as a primary travel mode for all trips, only $31 \%$ are made by public transport of which most of trips are completed by using bus. Travel share of other transit system viz. rail and water are very insignificant. Nearly $70 \%$ of all trips are made either by walk, rickshaw or non-transit modes etc [25]. It is to be mentioned here that the peak hour commuter movement of Dhaka city is mainly road based. Other alternative travel systems viz. rail and water has inherent weakness, as they are not aligned with the inner city commuter movement paths.

\section{i) Absence of automated and integrated traffic signals}

There are about 1932 nos. of signal lights points all over the streets of Dhaka City. The operational and maintenance cost of these lights is about 4 cores Taka. But this huge cost goes almost in vein, because in most of the cases the lights are not functioning now. The traffic police control the flow with the hands. In some cases traffic signals are found to be obscured by hoarding, billboards, branches of trees etc. [26].

\section{j) Poor interface provisions}

Deficiency in the provisions of interface is largely responsible for much of the operational problem of the city's transportation system. Passengers of buses require adequate and efficient facilities for changing mode to reach their ultimate destination. Most of them are served by rickshaws, baby taxis, tempos for this purpose. But bus and these modes are hardly linked and appropriately designed for efficient integrated services. Often a large swarm of rickshaws remain standing in bus-stands blocking the way for buses to move forward or come closer to the footpath. Again there provision for baby taxis, tempos, taxi-cabs to park properly and collect passengers from buses and thereby creating a chaotic situation at most of the bus stoppages in the city.

\subsection{Deficiencies from user point of views}

Most of the existing bus services are uncomfortable, inconvenient, and unsafe for the passengers. Most of the buses are owned privately and they operate it completely from commercial point view. They seek more and more profit and don't care about passengers' facilities. They always compete with other buses to pick up the passengers from route and try to get the pickup spot first and to do so; they often cause safety problems for passengers. During off peak hour, they wait for long time at bus stops to full the bus and cause a huge delay for passengers to get their destinations. There are many other difficulties for the people who are using the buses such as:

\section{a) Lack of passenger information}

Passenger information, in terms of route maps, schedules, or service time coverage, is virtually nonexistent. Furthermore, most buses are not identified by route number. Some are identified with display boards showing the origin and destination of the route. For the majority of buses in the city, however, passengers rely either on familiarity with the route, or on the instructions shouted out by the bus conductor/helper while the bus slows down or stops at bus stop. 


\section{b) Inadequate bus stops}

Bus shelters in Dhaka are generally absent, or, where provided, are generally unused (at least by bus passengers) and often in a derelict condition. Passengers waiting for buses do so in poor conditions unprotected from wind, rain, and sun or passing vehicles. Passengers waiting for buses in Dhaka generally do not have access to bus shelters, passenger information, shelter from weather, or any other facilities.

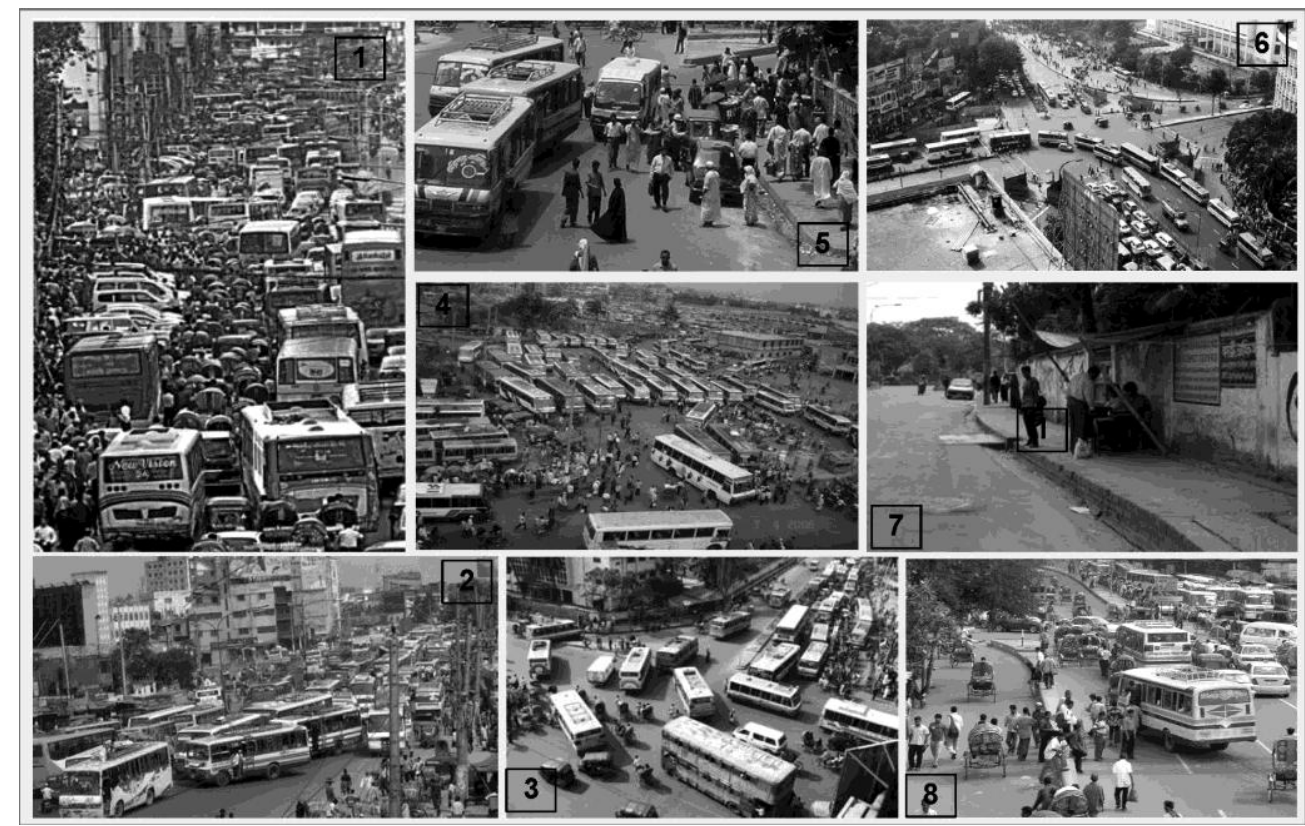

Figure 2: Deficiencies of existing bus system (Source: [27])

1. Mixed operations in major roads.

2. Inefficient road use.

3. Fragmented ownership.

4. Numerous small operators.

5. No proper bus stops.

6. Multiple operators competing in same route

7. Inadequate bus stops.

8. Safety issue.

\section{INTEGRATED HIERARCHICAL TRANSPORT NETWORK AS AN IMPROVEMENT OPTIONS}

The public transportation system in Metropolitan Dhaka is not only performing below standard as compared with other capital cities but it has also reached a crisis point that requires immediate attention. An intensive effort is needed from all concerned to resolve the city's transportation problem. The overall design of the public transport systems both public and private transport need to be re-planned and re-constructed.

Towards a better and effective public transport the first and most important aspect is to ensure an efficient and effective PT network. Towards this, the first step is to establish hierarchy of routes. The highest hierarchy should have a separate lane or dedicated route.

\subsection{Establishing hierarchy of PT routes:}

The network should have a certain logical hierarchy for PT routes. A new network and service concept has designed consisting of $\mathbf{3}$ layers. Each layer has a dedicated function with specific service characteristics. This hierarchy will be achieved by establishing backbone network, internal network and external network in study area as explained in table 1.

Table 1: Network hierarchy

\begin{tabular}{|l|l|l|}
\hline Layer & Location & Level of service \\
\hline 1 Backbone network & Main corridors & $\begin{array}{l}\text { Very fast, high frequency and high } \\
\text { capacity }\end{array}$ \\
\hline 2 Internal network & $\begin{array}{l}\text { Areas not served by } \\
\text { backbone }\end{array}$ & $\begin{array}{l}\text { Normal speed, normal frequency } \\
\text { and normal capacity }\end{array}$ \\
\hline 3 External network & $\begin{array}{l}\text { Direct line to other } \\
\text { districts }\end{array}$ & $\begin{array}{l}\text { Fast, medium or low and normal } \\
\text { or low capacity }\end{array}$ \\
\hline
\end{tabular}




\section{a) Backbone network:}

The backbone network (1st layer) consists of services on the main corridors in Dhaka. The backbone lines provides a high operational speed (high vehicle speed, relative long distances between stops and short dwelling times at bus stops) and have a high frequency. On the backbone network regular big buses (capacity between 60 and 80 passengers per vehicle) will operate. Within large metropolitan areas like Dhaka with a population of over 10 million, it is unsuitable and uneconomical to operate only one exclusive public transportation system [28]. From this viewpoint introduction of improved mass transit is important.

BRT: The first backbone is a proposal for a Bus Rapid Transport (BRT) system. There will be two BRT lines on identified major corridors, one is in north south direction and another one is in east west direction based on the analysis of demand and major hotspots, but with separate designated lane exclusive to bus system.

LRT: A large city, like Dhaka, especially when it reaches a stage where the concentration of travel demand cannot be efficiently handled by the road-based system, the development of an urban rail system becomes essential. From the experience of other mega cities, it can be said that road network alone cannot satisfy the need for transportation of such a large city. To cope with the problems of increasing transportation demand, traffic congestion, deteriorating environmental quality, and inadequate traffic safety measures Light Rail Transit can be a probable solution. Considering its potential, LRT proved a suitable solution to the present transportation need of Dhaka City as already an existing rail track is passing in the heart of the city. Rail-based mass rapid transit system along with efficient bus service can resolve the high transport demand in Dhaka. And also we know that the best solution is to have the city train system 'on ground', not over or under. Constructing and operating an extensive new underground or elevated rail network will be an extremely complex, expensive and time consuming for a developing city like Dhaka. So there is a potential of developing an integrated transport and urbanization scheme by upgrading the existing railway network and connecting it to a backbone network of new BRT routes of public transport for the greater Dhaka region.

Metro: The third network of the backbone is a proposal to develop some 20.8 kilometres of Metro system which will be elevated from the ground. It has been proposed in the STP plan that the METRO system will be developed which incorporated in this proposed backbone network. This line will run from Uttara to Saidabad via Mohakhali, Sonargoan Hotel and Motijheel should be up.

In the context of low income developing country, dedicated bus lanes and light rail transits seem to be the most realistic solutions for the urban transportation problem of metropolitan Dhaka. Once the system is in place, it is expected that people would not be interested to use their private cars anymore. The city and the economy will get tremendous relief from the vehicle pressure and reduction of fuel related pollutants respectively. The majority of the people could have easy access to them.

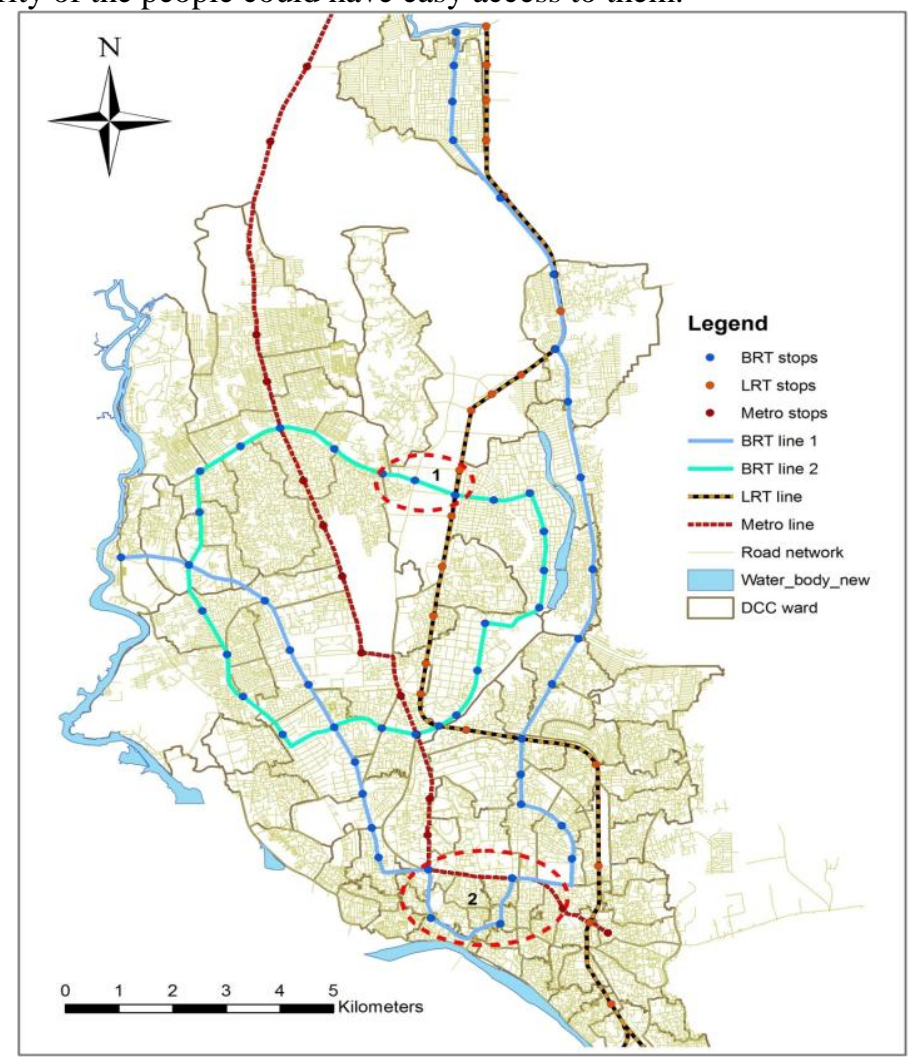

Figure 3: Proposed Backbone network (Source: Author) 


\section{b) Internal network/Feeder route:}

The internal network (2nd layer) consists of services to the areas that are not served by the backbone network. In general, the internal network services will serve the internal areas of Dhaka. The internal network will provide services with a normal speed with an interval between 7 and 15 minutes during peak hours and between 10 and 30 minutes during the day. On the internal network mini buses (capacity between 20 and 30 passengers per vehicle) will operate. Some of the existing bus route will operate as a feeder route as those routes are not served by the Backbone network.

\section{a) External network:}

Geographically the location of Dhaka is in the centre of the country and there are three gateways connecting the city with adjacent. As a result a lot of vehicle related traffic passes through the city creating anonymous pressure on city roads. That's why it's really necessary to differentiate these inter-district connections from city's own PT system. This external network (3rd layer) consists of direct fast services to different towns in the Dhaka district. Distances of lines are much longer than the internal network and depending on travel demand; frequencies will vary from 15-30 minutes in peak hour till 30-60 minutes during the day. Connections from the external network to the backbone network can be made either on Saidabad bus terminal (for southern corridor) or for some lines at the Gabtoli bus terminal (north western corridor). Outskirt connection from Dhaka is beyond the scope of study and due to the data limitations it's not possible to show the proposed external network.

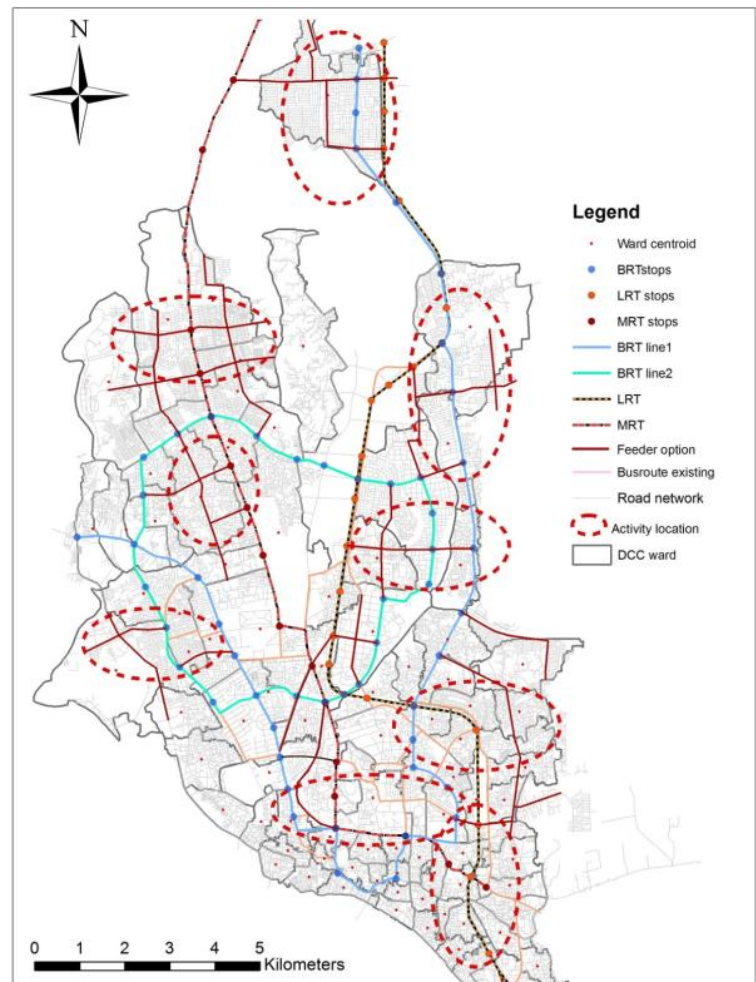

Figure 4: Feeder route layout (option)

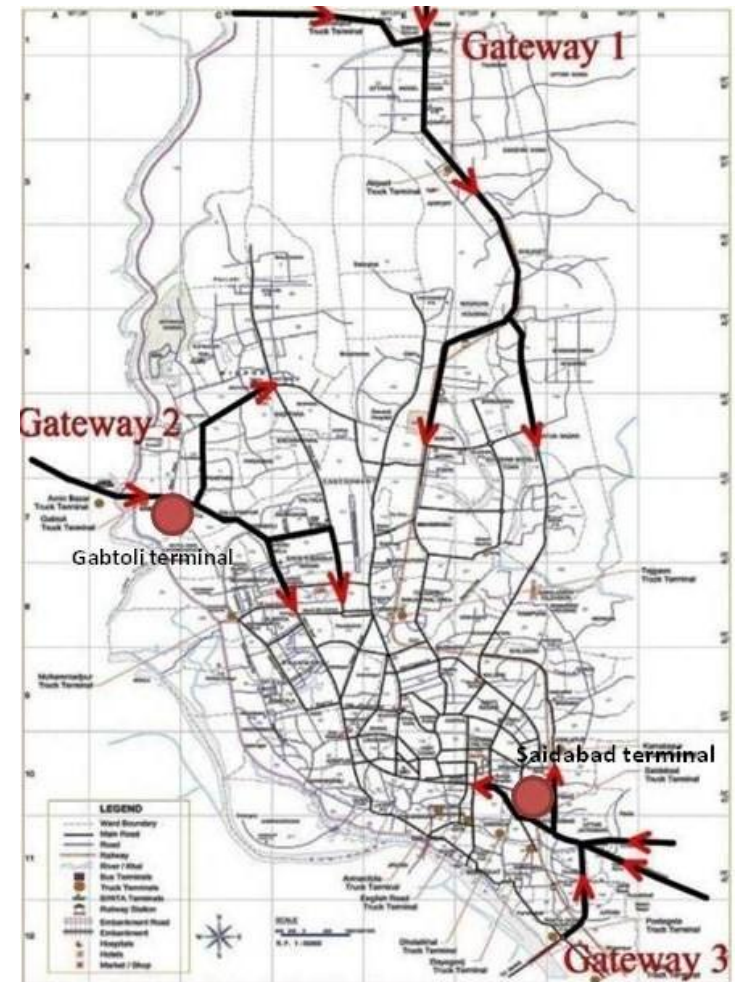

Figure 5: Dhaka city map showing three gateways

\subsection{Terminals and stops location:}

Source: [29]

Saidabad and Gabtoli terminal will be serve the south and north-west corridor and because of its central location Mohakhali terminal can also serve the route. But at the location of Farmgate a hub needs to create where BRT and LRT come together. It is necessary to establish an interchange station at this location. Keeping this in mind there is a possibility to create a multimodal terminal, as Saidabad terminal and Kamalapur rail station are almost together. The standard spacing for BRT stops vary from $0.5 \mathrm{~km}$ to $2 \mathrm{~km}$. In the proposed two BRT lines, the stops need to be located accordingly. Only a few existing stops can be adapted but they also need some modifications (permanent structure, sitting facilities, information display et.) and better facilities. Leading for the locations of the stops are the potential demand at those like a new residential area, a location of a major facilities. So BRT stop spacing will not be always within 500 meter varies from 500 meter to $1.5 \mathrm{~km}$. Bus stops need to be located at designated points only on the major roads, with locations for boarding and alighting passengers. 
For the proposed LRT the existing railway stations at Airport, Cantonment, Banani, Tejgaon, Kamalapur must be expanded to function as multimodal exchange nodes. New such stations will have to be constructed at the intersections of key roads and railway tracks at Mohakhali, Maghbazar, Panthapath and Rampura Road.

\subsection{Institutional framework}

The institutional capacity is known to be weak in the Dhaka Metropolitan Area, so it is important to ensure that the enabling legislation for the executing agencies is enacted, lines of responsibility are clearly defined and key staff appointments are made. There is a need to ensure that the current legislative conditions are suitable for the encouragement of private sector investment. There will need to be an independent review of current laws to ensure fairness on behalf of the private investor and protection for the Government. The Government will should provide an open and transparent bidding procedure to create fare competition within the bidding procedures. The Government need to provide the funds and other measures which will be needed to establish and maintain an up to date data base of both vehicles and drivers. The data base will be managed by BRTA but will be accessible to law enforcing agencies and safety engineers.

\subsection{Finance}

This integrated network will require investment in infrastructure to improve the existing roads, provide stations and fare collection gates and equipment. In order to finance the implementation of recommended backbone network required for the development of Metropolitan Dhaka, there are a range of possible options including creating a user charges system and providing equitable subsidies in the right manner and at as low a level as possible. There is a need to encourage loan financing from major international agencies. The private sector will also need to play a vital role in the promotion of private public partnerships. The program could be run as a totally public sector venture or as joint public and private sector initiative.

There is a need to introduce some form of easier fare structure in Dhaka city. This will not be easy under this existing weak institutional framework. An innovative but easily understandable mechanism need to be developed for the integration of fares between different type of backbone and feeder and also to develop the provision of a common ticketing system to allow free movement between different modes. This is also necessary to apply different strategies like discount fare for senior citizen, child etc. The fare structure will take account the length of trip and the type of service provided. Government need to take proper initiative to maintain this and to ensure an equitable fare structure for passengers.

\section{SOME POLICY GUIDELINES}

Below there are few policy guide lines and recommendations are provided towards achieving an efficient public transport system in Dhaka city.

a) Rationalize and harmonize the existing private sector buses into a number of limited companies and allocate major routes to one of these different companies. Each route will be served by only one company under a strictly set of rules and regulations. These would include number and types of buses to be used on each routes, frequencies of operation, fares to be charged, etc. No other buses or other companies will be allowed to ply on the designated routes.

b) Parking control should be the responsibility of the municipalities who will administer it through a central parking control office. The office will retain its own staff and will employ parking wardens to monitor space usage and issue tickets to violators. It is preferred that this aspect be undertaken by the private sector and the Government will enact such rules as will make this possible. And also need to provide and build as many parking-only structures (not mixed with other commercial uses) as possible on all major arterial roads of the city.

c) There should be investigate means whereby subsidies can be allocated to the poor and needy in order to make the transportation system affordable to all. Public transport of all kinds need to be planned and designed or adapted so as to provide some facilities in the vehicles so that disabled persons can access the vehicles and ride on them in comfort. The bus stations, terminals, railway stations and motor launch landing stations will be re-planned to provide proper facilities for disabled persons so that they do not encounter any impedance to movement.

d) Non-motorized transport will be prevented from operating on many sections of arterial highways and especially at intersections. Rickshaws will be encouraged and assisted to ply on the lanes and narrow roads to serve local neighborhood demands and to provide feeder services from the neighborhoods to the main line rapid transit stops.

e) Bicycles need to be recognized as a mode of transport and separate lanes and crossings will be provided within the city in order to make bicycle journeys safe and pleasant.

f) The Government need to enact a pedestrian policy to ensure the construction of properly designed and continuous pedestrians with well-defined and maintained pedestrian routes in the city, the provision of 
pedestrian crossing facilities giving the pedestrian priority over all other traffic and the prohibition of unauthorized encroachment on the footpath by street vendors and others.

g) The Government will initiate a comprehensive review of the existing laws and regulations as they apply to private sector investments and will amend the laws such that they provide equitable ways to enter into contracts between the parties.

The formulation of the most efficient plan and organizational set up will not be enough, is most essentially needed is the political will and determination of the Government.

\section{CONCLUSION}

In conclusion, Dhaka is an over densely populated city and its transport system is mainly road based with mostly non-motorized vehicles (predominantly rickshaw). Dhaka is experiencing lots of traffic congestion and a great lack of traffic management. Very few studies dealt with mass transit system in the metropolitan area. There has been no study dedicated to overcome the situation. The real hindrance to smooth traffic as experts look at it does not lie in inadequate roads. Dhaka's unplanned growth, a Dhaka-centric development of the country, the lack of east-west connecting roads, unplanned construction inside the city, increased number of private transports, the lack of mass transit are some of the contributory factors to these problem. Also transport service in Dhaka has several deficiencies resulting from a combination of factors - physical, developmental and institutional-cum-policy framework-related which lead to lower efficiency, higher transport costs, longer waiting \& travel time, discomfort and more significantly, "transport unreliability" with major adverse consequence for the economy \& environment. Rapid population growth, the absence of planning control and poor economic conditions has contributed to the lack of organization on the public rights-of-way. There is also a high level of operation disorder, which significantly diminishes the efficiency and effectiveness of the existing transport systems.

After analyzing the existing situation it is clear that without a collaborative Mass Rapid Transport (MRT) system the roads of Dhaka City will not be able to cope with the growing vehicles and expanded passengers in the near future and the whole transportation system will collapse. So to ensure proper network by proper mass rapid transit system is one way to solution the existing PT problem of Dhaka city. An integrated transport scheme with BRT, LRT and metro to achieve hierarchy are already discussed. This will be two BRT lines on grade on existing roads, but with separate designated lane exclusive to bus system. The existing railway stations and road intersections at Tongi, Airport, Cantonment, Banani, Tejgaon, Kamalapur and Naranyanganj must be expanded and rebuilt to function as multimodal exchange nodes. New such stations will have to be built at the intersections of the key roads and railway tracks at Mohakhali, Maghbazar, Panthapath and Rampura Road. Also feeder route need to integrate with the backbone system. To overcome these increasing transportation burdens and to meet the transport needs of residents and to promote desirable patterns of land use in Greater Dhaka over the next decades it is necessary to change the existing policies. However, organizational supports and infrastructure development needed to meet the demand of the mobility of the urban dwellers. Hopefully, hierarchy of routes and future proposed feeder access accordingly will help to PT Planner and experts to influence the performance of public transportation systems of Dhaka.

\section{REFERENCES}

[1] White. (2002). Public transport: its planning, management and operation. London: Newyork, spon press.

[2] Tiwari, G. (2002). Urban Transport Priorities: Meeting the Challenge of Socio-economic Diversity in Cities, a Case Study of Delhi, India "Cities", 19(2), 95-103.

[3] Beirão, G., \& SarsfieldCabral, J. A. (2007). Understanding Attitudes towards Public Transport and Private Car: A Qualitative Study. Transport Policy 14(6), 478-489.

[4] Palmner, C., Astrop, A., \& al., e. (1996). Attitudes and Travel Behavior of Households in Pune, India. International Symposium on Infrastructure of the Future. Bangalore, India. Transport Research Laboratory.

[5] Mackett, R. L. (2001). "Policies to Attract Drivers out of their Cars for Short Trips. Transport Policy, 8(4), 295-306.

[6] Nagari, A. T. M. H. (2001). Strategic Transport Planning for Dhaka Metropolitan Area.

[7] DUTP. (1998). Draft Final Report, Prepared by PPK. Dhaka: Mot MacDonald and Development Design Consultant (DDC),

[8] DDC. (1998). Dhaka Urban Transport Plan Phase II Consultancy Draft Final Report (Volume III): Environmental Action Plan (EAP): Development Design Consultants (DDC) and Mott MacDonald and PPK prepared for the Ministry of Transport, Government of Bangladesh.

[9] DDC. (1998). Dhaka Urban Transport Plan Phase II Consultancy Draft Final Report (Volume III): Environmental Action Plan (EAP): Development Design Consultants (DDC) and Mott MacDonald and PPK prepared for the Ministry of Transport, Government of Bangladesh.

[10] Rahman, M. S. (2008). Future Mass Rapid Transit in Dhaka City: Options, Issues and Realities. Jahangirnagar Planning Review, 6, 69-81.

[11] Karim, M. M. (1998). Engineering, Regulatory, and Financial Options for Mass Transit in Metropolitan Dhaka: Government of the People's Republic of Bangladesh.

[12] Ahsan, H. M. (1990). A Study of Mass Transit in Metropolitan Dhaka. BUET, Dhaka.

[13] STP. (2004). "Strategic Transport Plan(STP) for Dhaka, Final Report, 2006”: Dhaka Transport Coordination Board.

[14] Quium, A. S. M. (1995). Dhaka Metropolitan Development Plan, Review of Structures, and Urban Area Plans, Sub Sector: Transport. Paper presented at the Dhaka Metropolitan Development Plan, 
[15] DUTP- II. (1998). Draft Final Report, . Dhaka.: Prepared by PPK, Mot MacDonald and Development Design Consultant (DDC), .

[16] Rahman, G., Majumder, M. K., \& Rana, B. (1999). State of Air Pollution in Bangladesh.: Forum of Environmental Journalists of Bangladesh (FEJB).

[17] DMDP. (1995). Dhaka Structure Plan 1995-2015: Dhaka Metropolitan Development Plan, RAJUK

[18] DMDP. (1995). Dhaka Structure Plan 1995-2015: Dhaka Metropolitan Development Plan, RAJUK.

[19] Amin, M. S. R., Rahman, M. M., Uddin, M. Z., \& Maniruzzaman, K. M. (2005). State of Public Transport:An Analysis of Bus Routes and Stoppages of Dhaka City. Jahangirnagar Planning Review,, 3, 93-104.

[20] BRTA. (2002). Statistical List of Route Permit of Bus and Minibus in Dhaka City. Dhaka: Bangladesh Road Transport.

[21] Untermann, R. K. (1984). Accommodating the Pedestrians. New York: Van Nostrand Reinhold.

[22] Amin, M. S. R., Rahman, M. M., Uddin, M. Z., \& Maniruzzaman, K. M. (2005). State of Public Transport:An Analysis of Bus Routes and Stoppages of Dhaka City. Jahangirnagar Planning Review, 3, 93-104.

[23] RMMS. (2004). Road Maintenance and Management System (RMMS). Dhaka: Dhaka City Corporation (DCC).

[24] RMMS. (2004). Road Maintenance and Management System (RMMS). Dhaka: Dhaka City Corporation (DCC).

[25] DITS. (1994). "Dhaka Integrated Transport System (DITS)". Dhaka: Dhaka Transport Coordination Board (DTCB).

[26] JBIC. (2000). Study on the Improvement of Transportation and Environment in Dhaka: Japan Bank for International Cooperation.

[27] Hoque, M. S., \& Choudhury, C. F. (2009). Mass Transit System in Dhaka City. Paper presented at the Workshop on Future Direction of Dhaka Urban Transport.

[28] Ahsan, H. M. (1990). A Study of Mass Transit in Metropolitan Dhaka. BUET, Dhaka.

[29] Hoque, M. S., \& Choudhury, C. F. (2009). Mass Transit System in Dhaka City. Paper presented at the Workshop on Future Direction of Dhaka Urban Transport. 